\title{
Column 2 \\ Variations of Short-Lived Climate \\ Pollutants in Hanoi, Vietnam
}

\author{
Tung Duy Do and Kazuyuki Kita
}

Emissions of air pollutants have been increasing significantly in Asian countries due to the rapid development of industry and economy. Long-range, transboundary transport of these pollutants probably affects the atmospheric environment and the regional climate in this region (Kita et al. 2009). Climate change, air pollution, and sustainable development are inter-linked, and co-benefits of cutting short-lived climate pollutants (SLCP) will avoid global warming higher than $1.5^{\circ} \mathrm{C}$ and negative trade-offs (CCAC 2019; IPCC 2018). Therefore, identification of SLCP emission/ production/ transportation sources is critical for planning mitigative measures to reduce SLCP.

In this study, simultaneous observation of black carbon (BC), tropospheric ozone $\left(\mathrm{TO}_{3}\right)$ and particulate matter $2.5\left(\mathrm{PM}_{2.5}\right)$, which are significant climate forcers, was carried out at VNU Vietnam Japan University in Hanoi to clarify the concentrations and variations of SLCP in Hanoi and Northern Vietnam. The research applied HYSPLIT trajectory model to distinguish contribution source regions of SLCPs to Hanoi and deployed remote $\mathrm{PM}_{2.5}$ stations surrounding Hanoi and coastal region in Northeast sector of Northern Vietnam to compare upwind and downwind concentrations.

Figure $\mathrm{C} 2.1$ shows the maximum episodes of $\mathrm{BC}$ and $\mathrm{PM}_{2.5}$ observed in wintertime, especially in January with periods lasting from 1 day to 1 week. Monthly averaged concentrations of $\mathrm{BC}, \mathrm{TO}_{3}$ and $\mathrm{PM}_{2.5}$ were in range of $1-3 \mu \mathrm{g} / \mathrm{m}^{3}, 20-50$ ppbv and $18-65 \mu \mathrm{g} / \mathrm{m}^{3}$, respectively (Fig. C2.2). BC concentration was estimated

\footnotetext{
T. D. Do

VNU Vietnam Japan University, Hanoi, Vietnam

K. Kita $(\bowtie)$

Graduate School of Science and Engineering, Ibaraki University, Ibaraki, Japan

e-mail: kazuyuki.kita.iu@vc.ibaraki.ac.jp
} 


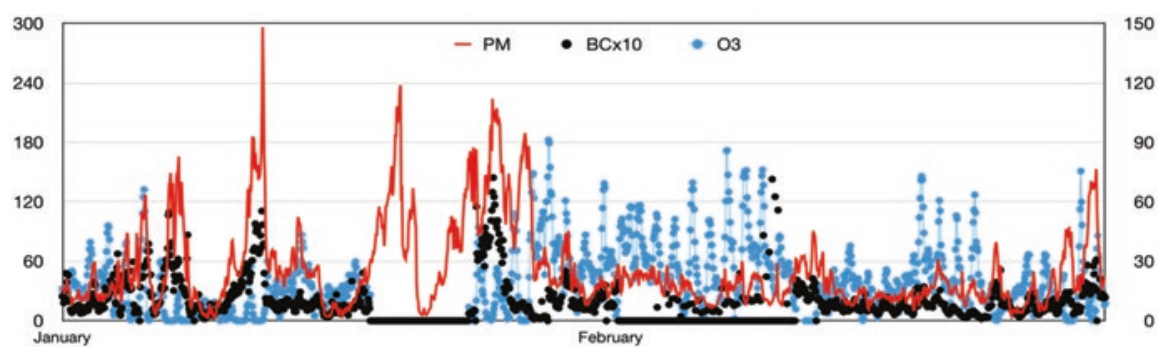

Fig. C2.1 Timeseries of $\mathrm{BC}, \mathrm{TO}_{3}$ and $\mathrm{PM}_{2.5}$ in Hanoi in Jan. and Feb., 2019

from $4 \%$ to $6 \%$ of PM2.5 in all seasons of 2019. Diurnal variations of these species suggested that major part of them were emitted or produced in Northern Vietnam region. $\mathrm{BC}$ and $\mathrm{PM}_{2.5}$ were remarkably increased during rush hours or night-time in diurnal variation. In contrast, $\mathrm{TO}_{3}$ was often high at noon and depleted to zero at night. Seasonal variation as shown in Fig. C2.2 indicated that BC and $\mathrm{PM}_{2.5}$ increased with winter monsoon, and $\mathrm{TO}_{3}$ actively produced in summer, indicating that air transport in association with the winter monsoon affected concentration of $\mathrm{BC}$ and $\mathrm{PM}_{2.5}$ in this region. Due to observed enhances of $\mathrm{BC}$ and $\mathrm{PM}_{2.5}$ in 2019 , the comparison analysis with local and regional transport features focused on wintertime (Fig. C2.3). These high rises were mostly associated with trajectories from South China Sea, and detailed analyses of relation between these rises and the calculated trajectory routes revealed that these rises were actually attributed to emissions from North East coastal region of Northern Vietnam.

In REAS inventory data set (Kurokawa and Ohara 2020), national BC emissions in Vietnam was estimated as $59 \mathrm{Tg} / \mathrm{y}$ in 2015, second largest in ASEAN countries. Given the significant climate forcing of BC, this study strongly suggests that mitigation measures to reduce $\mathrm{BC}$ in Vietnam can considerably improve both regional climate change and air quality in the Northern Vietnam region. 

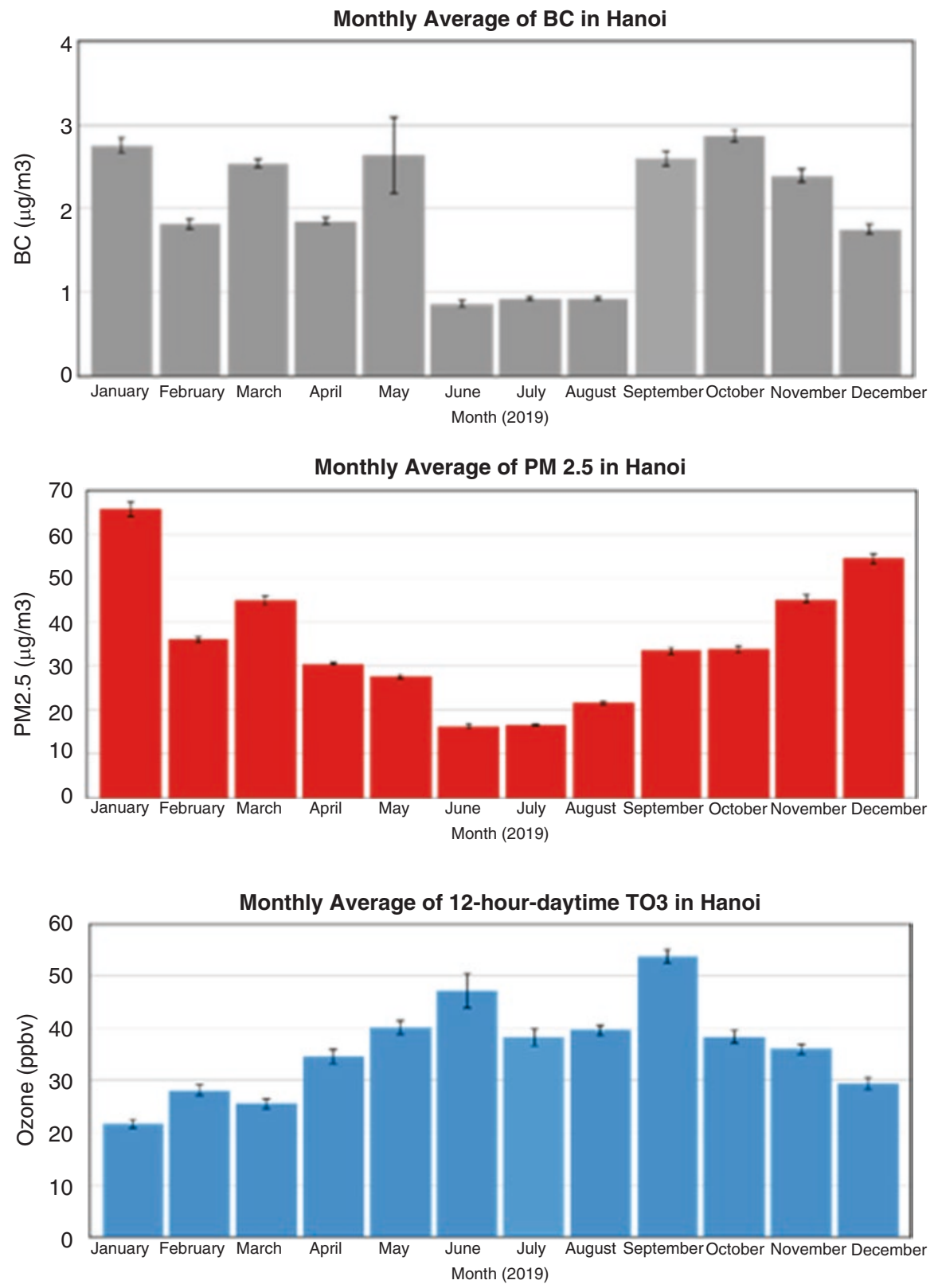

Fig. C2.2 Monthly average of $\mathrm{BC}, \mathrm{PM}_{2.5}$ and $\mathrm{TO}_{3}$ in Hanoi in 2019 


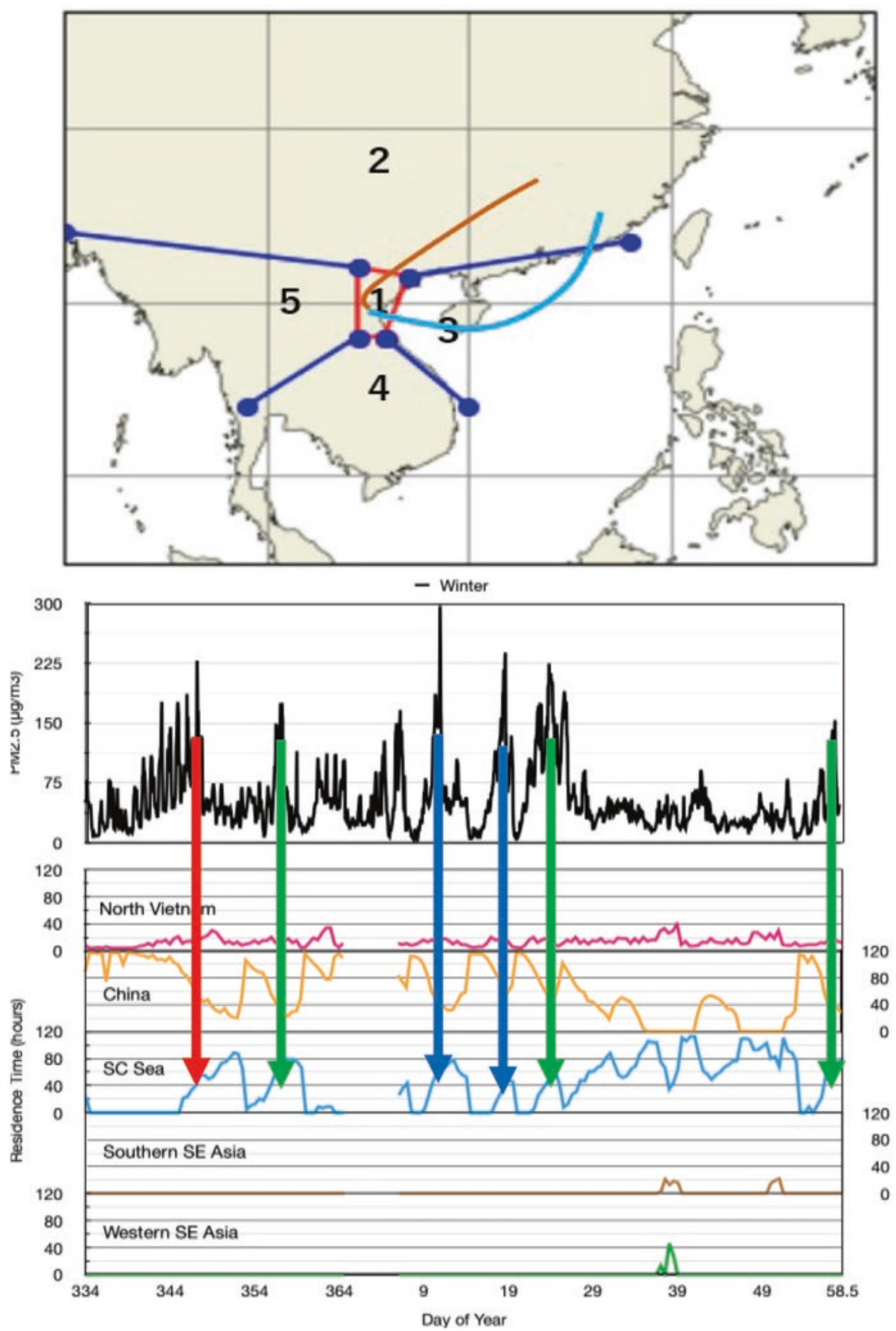

Fig. C2.3 Relation of $\mathrm{PM}_{2.5}$ concentration with air mass transport trajectories and residence time in areas around Northern Vietnam 


\section{References}

CCAC (2019) Climate and clean air coalition to reduce short lived climate pollutants. (2019, March 15). http://www.ccacoalition.org/en/content/short-lived-climate-pollutants-slcps

IPCC (2018) Global warming of $1.5^{\circ} \mathrm{C}$. An IPCC Special Report on the impacts of global warming of $1.5^{\circ} \mathrm{C}$ above pre-industrial levels and related global greenhouse gas emission pathways, in the context of strengthening the global response to the threat of climate change, sustainable development, and efforts to eradicate poverty (Masson-Delmotte V, Zhai P, Pörtner HO, Roberts D, Skea J, Shukla PR, Pirani A, Moufouma-Okia W, Péan C, Pidcock R, Connors S, Matthews JBR, Chen Y, Zhou X, Gomis MI, Lonnoy E, Maycock T, Tignor M, Waterfield T (eds)). In Press

Kita K, Kasai Y, Sagi K, Hayashida S, Irie H, Kanaya Y, Miyazaki K, Takigawa M, Noguchi K, Kondo Y, Koike M, Akimoto H (2009) Transboundary air pollution in East/Southeast Asia and geostationary measurement. AGU Fall Meeting Abstracts

Kurokawa J, Ohara T (2020) Long-term historical trends in air pollutant emissions in Asia: Regional Emission inventory in ASia (REAS) version 3. Atmos Chem Phys 20:12761-12793. https://doi.org/10.5194/acp-20-12761-2020

Open Access This chapter is licensed under the terms of the Creative Commons Attribution 4.0 International License (http://creativecommons.org/licenses/by/4.0/), which permits use, sharing, adaptation, distribution and reproduction in any medium or format, as long as you give appropriate credit to the original author(s) and the source, provide a link to the Creative Commons license and indicate if changes were made.

The images or other third party material in this chapter are included in the chapter's Creative Commons license, unless indicated otherwise in a credit line to the material. If material is not included in the chapter's Creative Commons license and your intended use is not permitted by statutory regulation or exceeds the permitted use, you will need to obtain permission directly from the copyright holder. 